sanitary, so that San Francisco may be able to claim that it is not behind other cities, either in charity or Christian care for the sick and suffering poor of one of the most beautiful cities of the world. We shall be very glad if our contemporaries in San Francisco will kindly keep us informed from time to time of the steps taken to secure adequate and proper hospital accommodation for the poor of the capital of California.

\section{FURNITURE AND FITTINGS.}

BRONCHIIIS OR TRACHEOTOMY KETTLE.

Our illustration shows an excellent kettle supplied by Messrs. Mayer and Meltzer, and is the invention of Mr. Newton H. Nixon, Secretary of University College Hospital. This kettle does away with the necessity for waterproof sheeting over the bed, as it is designed to carry off the condensed steam.

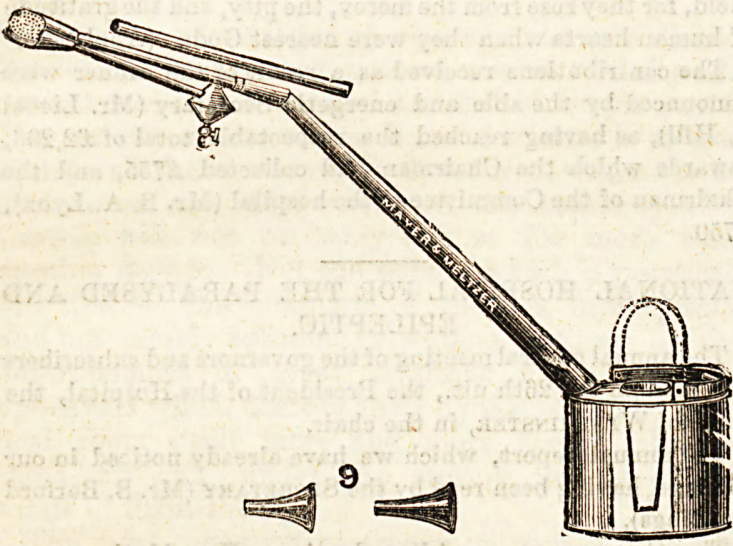

No lid is required. The kettle is heated over a gas-ring, and not on the fire, although it can be used in either way. It can be placed in any part of a ward or room by regulating the length of india-rubber tubing. The kettle can be adapted for use by either adults or children as the spout is made in sections.

\section{BUCKET FIRE EXTINGUISHER.}

Fire buckets are essentials in all public and private institutions, and the space necessarily occupied by them, together with their liability to misuse and the oft required refilling has always been a disadvantage. Our illustration

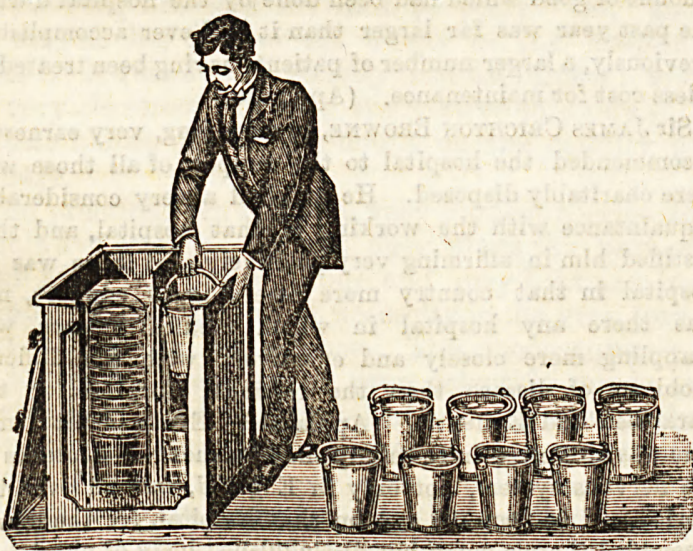

shows a means by which all these inconveniences are remedied. By this unique system of telescoping the buckets together beneath the water in a covered receptable, 10, 20, 30 , or more buckets can be compactly stored in a very small space. The buckets, by the ends of their handles sliding in channels, are guided into and held in position ; they are instantly released by the action of raising their handles when lifting them out. So guided and retainsd it is impossible for a bucket to become in any way displaced or jammed, or to be lifted by the suction caused by the withdrawal of the bucket above it. By this simple arrangement the buckets on being withdrawn pick up their water and come out full, ready for immediate use, and can be taken in succession with the ut. most rapidity. As the water and the buckets are in a closed vessel under seal (only to be broken in the event of fire) they are both perfectly protected from misuse. The cover of the tank being airtight, there is no evaporation of the water, nor that danger of freezing as with exposed buckets, and with the addition of a little disinfectant (such as Condy's fluid, permanganate of potash, \&c.) the water may remain in the tank for quite twelve months without being ehanged or requiring any attention whatever. The Bucket Fire Extinguisher has no complicated parts, taps, or other fittings, liable to get out of order through long disuse. It is very compact, occupying so small a space that it can be placed álmost anywhere, and may be made-where its normal appearance might be considered inadmissible-in the form of a pedestal, sideboard, settee, seat, \&c., en suite with the furniture. It will be seen from the simplicity and com. pactness of the apparatus that its sphere of application is exceedingly wide and varied. The manufacturers of the Extinguisher are Messrs. Messer and Thorpe, Quality Court, Chancery Lane, and prices range from $£ 77$ s. to $£ 17$.

\section{FESTIVAL DINNERS AND HOSPITAL MEETINGS.}

\section{CITY OF LONDON HOSPITAL FOR DISEASES OF THE CHEST.}

The festival dinner in aid of the above hospital was held at the Hotel Metropole on the 24th ult., the Earl of Strafford, Lord Lieutenant of the County of Middlesex, presiding. Among those present were over one hundred representatives of the several societies who contribute to the funds of the hospital.

The Chairman, in proposing the toast, " Prosperity to the City of London Hospital for Diseases of the Chest," said that twenty-five years ago he had had the honour of presid. ing at a previous festival dinner, and he hoped they would believe him when he said that the sympathy with that insti. tution which he felt in the year 1865 was felt equally by him in the year 1892. That institution was first established in the month of June, 1848, by an out-patients' branch being founded in Liverpool Road. In June, 1851, the foundationstone of the hospital in Victoria Park was laid by the late lamented Prince Consort, and the hospital was opened for the reception of patients in the year 1855 . New wings had been subsequently added in 1863 and 1871. During 18911,236 in-patients had been treated, making the total number of this class of patients who had been admitted since 185525,000 . Those resident in the hospital during 1891 averaged 122 daily. During the same period 15,529 out-patients had been treated, making the number treated since the foundation of the institution in 1848 489,890 . The average attendance of out-patients each week was 1,066. The annual expenditure was $£ 10,000$, towards which there were annual subscriptions (including the grants from the Hospital Sunday and Saturday Funds) to the tune of $£ 3,500$, and invested funds of only $£ 300$. The past year's expenditure had exceeded the income by $£ 2,848$. Contracts, as he had no doubt his readers were aware, had been entered into, and were now in course of completion, for the erection of new blocks for improving the ventilation and sanitary arrangements. A special feature of the institution well worthy of note by him was the fact that it was so liberally and generously supported by the working men of the neighbourhood, who gave $£ 900$ a year towards the income 
of the hospital. Possibly no hospital did so much for the sick and suffering as the Chest Hospital. No less than one-ninth of the mortality of all ages, and one-fifth of that of adults of the United Kingdom was attributed to consumption, and when they looked back on the last three years and thought of the frightful suffering which had been inflicted by that terrible disease, the influenza, he was quite certain that everyone must feel that a great hospital like the one whose cause he was pleading was doing an incalculable amount of good. (Applause.) In conclusion, he exhorted his hearers to try and enlist the sympathy and support of their relatives and friends in the great and good work which, under the blessing of Providence, thatinstitution had managed to do. An institution, he said, which, since 1848, had contributed to the relief of half-a-million of people would not, he was sure, be allowed to fail for want of funds. (Applause.)

A total contribution of $£ 2,584$ was announced by the Secretary.

\section{NORTH LONDON HOSPITAL FOR CONSUMPTION.}

The festival dinner in aid of the funds of this institution was held at the Hotel Metropole on the 2Sth ult., Mr. HeNRY IRving in the chair. A certain amount of freshness and novelty was imparted to the proceedings by the fact that the guests were not altogether of the class which one usually meets at hospital dinners. For, besides Members of Parliament, medical men, County Councillors, and philanthropists, who are always present on auch occasions, there were to be seen representatives of art, literature, music, play.writing, and all branches of that profession of which the Chairman is so eminent a member.

Mr. HENRY IRVING, who was most warmly received, in the course of an ex zellent speech on behalf of the institution, said that the North London Consumption Hospital made a stronger appeal to their common humanity at the present time than it ever did before. A year ago the world was startled by the news of a great discovery; it was thought that that fell disease, consumption, was baffled at last; that a German physician had found the precious means of arresting it, at least in its earliest stages, and snatching the sufferer from the brink of the grave. No one could ever forget the joy which this seeming messenger of deliverance bore on its wings over both hemispheres. (Hear, hear.) Alas, rejoicing was premature, and the talisman against a cruel malady had yet to be charmed by science out of the secrets of Nature. But this very disappointment ought to give new zest to their efforts to provide every solace, every palliative, everything that medical skill had mastered for the relief of their fellowcreatures, who, in the midst of a dire misfortune, had been robbed of so great a hope. (Hear, hear.) He knew nothing in human history more pathetic than this story of Dr. Koch's failure, a failure which all must pray might prove to be the prelude of a triumph which would spread more beneficence throughout the earth than had ever been achieved by the arts of government. (Applause.)

"How small of all that human hearts endure,

That part which kings or laws can cause or cure."

But, in the meantime they knew their duty. They could not avert disease, but they could try to mitigate it and assuage its pains. (Hear, hear.) They could aid those who struggled through darkness into light, and assisted beneficent nature in restoring shattered strength, and they might help to lessen the pain of the sufferers by at least making their surroundings less terrible. (Hear, hear.) The North London Hospital for Consumption was an institution which was the need of a great city, for to the great city came many whose own poorer and less highly organised localities could not afford the opportunities for special treatment. The North London Hospital was thought of and wrought for in no mean or local spirit. It stocd "four-square to all the winds that blow," and on each and every side was a portal open to the afflicted. (Applause) It was so strong in its purpose that it violated with intention even the Scriptural canon regarding the choice of a site. True, it was a house set on a hill, for so it lifted its head high over the London fog and damp, and so gave life and vigour to those poor souls to whom to breathe the damp air was death-but it was not built on a rock. If they would find a fault with the organisers of this great charity, they might do so for this, that they had chosen to build their house on sand. For this monument of the piety of the rich and poor alike sprang from that island of Bigshot sand, which lifted itself above the wilderness of London clay. (Laughter.) But he could assure them that though the hospital was built on sand, the foundations were all right. (Applause.) They had a firmer base than any earth could yield, for they rose from the mercy, the pity, and the gratitude of human hearts when they were nearest God. (Applause.)

The contributions received as a result of the dinner were announced by the able and energetic Secretary (Mr. Lionel F. Hill), as having reached the respectable total of $£ 2,296$, towards which the Chairman had collected $£ 755$, and the Chairman of the Committee of the hospital (Mr. B. A. Lyon), $£ 750$.

\section{NATIONAL HOSPITAL FOR THE PARALYSED AND EPILEPTIC.}

The annual general meeting of the governors and subscribers was held on the 26th ult., the President of the Hospital, the Duke of WestMINSTER, in the chair.

The annual report, which we have already noticed in our columns, having been read by the Secretary (Mr. B. Burford Rawlings),

The Chairman moved its adoption. He said the report. began and ended with references to the extended require. ments of the hospital. As it was, so many would-be patients had to be refused for want of adequate space, that the board very reasonably to his mind, looked to an enlargement of the premises in a certain direction, which was not to be mentioned. Of course, in so doing they would not fail to remember that if the hospital was enlarged there came the question of increased means (which were not always so readily forthcoming) to maintain the wards and to maintain the increased number of patients. That was a difficulty, and it called for the earnest consideration of the board. The amount of good which had been done by the hospital during the past year was far larger than it had ever accomplished previously, a larger number of patients having been treated at a less cost for maintenance. (Applause.)

Sir James Crichton Browne, in seconding, very earnestly recommended the hospital to the support of all those who were charitably disposed. He had had a very considerable acquaintance with the working of that hospital, and that justified him in affirming very positively that there was no hospital in that country more deserving of support, nor was there any hospital in which medical science was grappling more closely and effectively with the difficult problems of disease than the National Hospital for the Paralysed and Epileptic. (Applause.) Every medical man who was interested in the study and treatment of disorders of the nervous system, not only in England, but all over the world, had to keep an eye on that hospital, for there was assembled there a small but distinguished body of physicians and surgeons, who, acting as pioneers through the dismai forest of neurotic disorders, had already opened up vistas of hopefulness in directions where everything before was dark and dismal. (Applause.)

The retiring members of the board, the Hon. H. D. Ryder and Mr. A. L. Wheeler, and the auditors, were re.elected. Ten pensioners were elected upon the fund for incurables, and various votes of thanks were passed. 